\title{
URBANISMO EN LA CIUDAD CRISTIANA: LOS ARCHIPIÉLAGOS CONVENTUALES DE LA CIUDAD DE PALMA*
}

\author{
POR \\ MARGARITA NOVO MALVÁREZ ${ }^{1}$ \\ Universitat de les Illes Balears
}

\section{RESUMEN}

Los conventos establecidos en Palma durante la Edad Media y Moderna fueron importantes centros espirituales, económicos y de poder que, además, influyeron considerablemente en la morfología urbana. Estos conventos dieron forma a la ciudad conventual y han dejado su impronta en la imagen actual. El estudio de su localización y distribución espacial es de gran relevancia para profundizar en el urbanismo de la ciudad y objetivo principal de este artículo. La secuencia continuada de conventos en determinadas áreas nos ha llevado a establecer archipiélagos conventuales que constituyen el rasgo morfológico más característico de la ciudad conventual palmesana.

PALABRAS CLAVE: ciudad conventual; Palma; conventos; fundaciones religiosas; archipiélago conventual; transformaciones urbanas.

\section{URBANISM IN THE CHRISTIAN CITY: THE CONVENTUAL ARCHIPELAGOS IN THE CITY OF PALMA}

\begin{abstract}
The convents established in Palma during Middle and Modern Ages were important spiritual, economic, and authority centers. The morphology of the city was influenced by the convents. They created the conventual city and left their mark on the present image. The study of the location of the convents and their spatial distribution is of great relevance for understanding the urban planning of the city, and it is the main objective of this article. The continuous sequence of convents in certain areas of Palma has led us to establish different conventual archipelagos that constitute the most characteristic morphological feature of the conventual city of Palma.
\end{abstract}

KEY WORDS: convent city; convents; religious foundations; conventual archipelago; Palma; urban transformations.

Cómo CITAR ESTE ARTículo / CitATION: Novo Malvárez, M. 2019. «Urbanismo en la ciudad cristiana: los archipiélagos conventuales de la ciudad de Palma». Hispania Sacra 71, 143: 259-270. https://doi.org/10.3989/hs.2019.019

Recibido/Received $\quad 10-06-2017$
Aceptado/Accepted

\section{PRESENTACIÓN}

La riqueza de los conventos palmesanos se relaciona con la importancia y solidez de la antigua ciudad conventual,

\footnotetext{
*Este artículo se integra en el plan de investigación actualmente en curso, correspondiente al proyecto: HAR2015-66307-P. «Estrategias documentales aplicadas a los procesos de restauración y divulgación del patrimonio artístico religioso de Mallorca» (AEI/FEDER/UE). Proyectos de I+D, del Programa Estatal de Fomento de la Investigación Científica y Técnica de Excelencia. Subprograma Estatal de Generación del Conocimiento. Ministerio de Economía y Competitividad. Gobierno de España. Unión Europea. Fondo Europeo de Desarrollo Regional.

1 m.novo@uib.es/ORCIDiD:https://orcid.org/0000-0001-8372-8088
}

de la que es heredera la urbe actual. El interés que ha tenido Palma como ciudad-convento en las edades Media y Moderna, en donde llegó a haber treinta fundaciones religiosas contrasta, sin embargo, con la escasa atención que se ha prestado a este tema desde un punto de vista académico. Hasta la fecha no se ha abierto una línea de estudio centrada en esta tipología de ciudad tal y como se ha potenciado en otras urbes españolas, como Sevilla, Córdoba, Granada, Valencia o Segovia. ${ }^{2}$ Si bien algunos cenobios

2 Autores que han hecho aportaciones sobre la localización y distribución conventual en sus respectivas ciudades han sido: Barrio Gozalo 1995; Noguera Giménez 2000; Olmedo Sánchez 2012; Pérez 
han sido estudiados de manera individual, sus autores han desarrollado principalmente cuestiones históricas o histórico-artísticas sin atender al papel fundamental que desempeñaron estas instituciones en el orden urbano. ${ }^{3}$ La Comunidad Autónoma de Andalucía constituye el territorio en donde ha habido más contribuciones y donde todavía se mantiene un alto porcentaje de instituciones conventuales que continúan activas. Por su parte, Sevilla fue la ciudad que llegó a tener más conventos de España (sesenta y ocho en la Edad Moderna), en tanto que Palma ocupó la doceava posición en el mismo periodo (Atienza 2009: 54). ${ }^{4}$

En este sentido y siguiendo otros ejemplos, el objetivo de este artículo es dar respuesta a cuestiones diversas que tienen como epicentro el conocimiento de la ciudad conventual palmesana y la localización de los conventos. Las preguntas que nos hemos planteado al comienzo de la investigación han sido las siguientes: ¿en qué circunstancias se origina la ciudad-convento y cuándo se produce su consolidación?, ¿qué actuaciones urbanas han influido en mayor medida en la localización de los conventos?, ¿en qué barrios o sectores urbanos se han localizado?

En función del objetivo que nos hemos marcado, el trabajo se estructura en cuatro partes, en donde avanzamos de aspectos generales hacia otros más específicos. Tras esta breve presentación y la explicación de la metodología a seguir, se desarrolla el primer apartado en donde hacemos una pequeña contribución al conocimiento de la ciudad conventual palmesana, teniendo especialmente en cuenta las principales intervenciones urbanas que han tenido lugar entre los siglos XIII y XIX. En el segundo centramos el análisis en la localización de los conventos. En el tercero nos aproximamos al mapa conventual, tratando de delimitar cuáles fueron los archipiélagos de mayor entidad en el contexto de la ciudad moderna. El artículo se cierra con las síntesis y conclusiones, tras las cuales se reseña la bibliografía consultada.

\section{Metodología, ámbito de estudio y marco cronológico}

Una de las formas más precisas de conocer una ciudad es estudiar su evolución urbana a través de la cartografía histórica. En Palma, se ha conservado una rica colección de planos generados a partir del siglo XVII que nos remiten al peso que aquí tuvo el estamento religioso. Su análisis nos

Cano 1996; Pérez Cano y Mosquera Adell 1991 y Rodríguez Molina 2012.

3 Las monografías publicadas por María José Bordoy (2009), María Magdalena De Quiroga (2014), Josep Estelrich (2002), Aina Pascual y Jaume Llabrés (1996) y Joan Carles Sastre (2006) constituyen fuentes principales para el estudio de algunos de los conventos palmesanos. A estas hay que añadir la obra firmada por Donald G. Murray, Aina Pascual y Jaume Llabrés (1992), un trabajo de conjunto que destaca tanto por la información histórico-artística que contiene como por la calidad de las fotografías de los conventos. Otras contribuciones de interés han visto la luz en una obra colectiva coordinada por María Barceló e Isabel Moll (2004) con motivo de la celebración de las XXI Jornades d'Estudis Històrics Locals celebradas en Palma en 2003.

4 Un listado de ciudades españolas con el número de conventos es proporcionado por Ángela Atienza (2009: 54). La relación es la siguiente: Sevilla con 68 conventos, Madrid con 64, Valencia y Valladolid con 49 cada una, Barcelona con 47, Zaragoza con 44, Córdoba con 43, Toledo y Granada con 41, Salamanca con 38, Alcalá de Henares con 31, Palma de Mallorca con 27, Málaga con 25, Murcia con 24, Burgos y Segovia con 23, Jerez de la Frontera con 22 y Écija con 21. ha permitido visualizar el proceso de implantación conventual. Una buena parte de esta cartografía se ha reunido en la obra de Juan Tous Meliá (2002) Palma a través de la cartografía (1596-1902). En los planos y mapas, además de las plazas y edificios públicos, se señalan iglesias, hospitales y conventos.

A la consulta de la cartografía se ha añadido la revisión de documentación y bibliografía relacionada con este tema. Otro método de análisis ha consistido en la elaboración de mapas en donde hemos localizado los establecimientos conventuales con la intención de destacar la importancia que han tenido estas instituciones en la estructura de la ciudad.

El ámbito de estudio es el antiguo espacio intramuros de Palma y la zona extramuros más próxima. El marco cronológico se ha circunscrito a un periodo amplio, que abarca siete siglos. El punto de partida lo situamos en 1229, por ser la fecha en que tuvo lugar la conquista de Mallorca por Jaime I. En este momento se produjo la cristianización de la ciudad y se establecieron los primeros claustros. El final de esta etapa lo marca la crisis del sistema conventual a raíz de la aplicación de las medidas desamortizadoras que tuvieron lugar en el siglo XIX, entre las que destacamos la supresión de todos los conventos masculinos de la ciudad.

\section{LA CONSTRUCCIÓN DE LA CIUDAD CONVENTUAL}

Palma fue una urbe que, desde el momento de la conquista, dio cabida a pluralidad de vocaciones. El proceso de construcción de la ciudad conventual comenzó en el siglo XIII y continuó en las centurias siguientes, siendo especialmente intenso durante los siglos XVI y XVII.

Una vez liberada Mallorca del dominio árabe que duró algo más de tres siglos (902-1229), comenzó el proceso de implantación de las parroquias, controladas por el arzobispo y el clero secular, y de los primeros conventos donde se insertó el clero regular. Parroquias y conventos se convirtieron, de este modo, en agentes fundamentales para la transformación de la ciudad conquistada. Entre las actuaciones más simbólicas que tuvieron lugar después de la victoria cristiana destaca la sustitución de mezquitas por iglesias y de torres por minaretes. Una medida que, tras ser aplicada, provocó profundos cambios en el paisaje urbano palmesano. La historiadora Margalida Bernat cifra entre treinta y ocho y cuarenta y ocho el número de mezquitas existentes en Palma en el siglo XIII y, al menos, cinco baños relacionados con ellas. Esta autora indica que algunas fueron inmediatamente desafectadas mientras que otras, como la que estaba en el lugar que ocupó parroquia de San Miguel o sobre la que se construyó la propia catedral, se consagraron como iglesias cristianas (Bernat 2010: 16). Estas acciones, basadas en ocupar los principales lugares simbólicos como signo de evangelización, las veremos reproducidas en otras muchas ciudades españolas como Sevilla, Córdoba, Cáceres, Valencia, Cuenca, Toledo o Almería. ${ }^{5}$

5 Este tipo de estrategia volverá a ponerse en práctica en Palma en otros momentos históricos, como se ejemplifica en el convento de Nuestra Señora de Monti-sión, fundado en el siglo XVI sobre los restos de una antigua sinagoga judía. La llegada de los jesuitas a Mallorca (1561) y la fundación del convento ha sido estudiada por Mercè Gambús (1997: 6-7). 
Las primeras parroquias de Palma fueron erigidas por el obispo de Barcelona, Berenguer de Palou, como privilegio por haber asistido a la conquista, en virtud de una bula expedida por Inocencio IV en abril de 1248. Estas fueron Santa Eulalia y San Miguel en la parte alta de la ciudad, y San Jaime y Santa Cruz en la parte baja. En 1302 se añadió la parroquia de San Nicolás, que ocupaba un espacio intermedio. La sexta y última fue la de la Almudaina al final del siglo XVI (Barceló 1985: 1322).

Los conventos, en su mayoría pertenecientes a órdenes mendicantes, se situaron preferentemente en el espacio intramuros y además de modificar los sectores próximos a su emplazamiento, influyeron en la construcción de un determinado modelo de ciudad. ${ }^{6}$ Poco a poco fueron imponiendo un orden, mediante la obtención de una preponderancia urbana que le permitía ordenar urbanísticamente las calles que los circundaban.

En primer lugar y, siguiendo la tendencia constatada en otras urbes peninsulares, se dio preferencia de fundación a las órdenes militares que acompañaron al rey Jaime en la conquista y ayudaron en la contienda bélica. Por tal motivo, los primeros conventos en establecerse fueron el del Temple (1230), San Francisco de Asís (1230) y Santo Domingo (1231). Otros cenobios cuya presencia se constató desde fechas tempranas fueron el de Nuestra Señora de la Merced (1295) y el de Nuestra Señora del Carmen (1321). Entre los femeninos, los precursores fueron el de Santa Margarita (1232), Santa Clara (1256) y Santa Magdalena (1320).

En la Edad Moderna se constataron nuevas fundaciones y se consolidó el modelo de ciudad conventual. Con la llegada del siglo XVI aumentó la actividad, tanto constructora como renovadora, impulsada por razones de prosperidad económica a causa del desarrollo del comercio, y por el refuerzo a la religiosidad emanada desde Trento. Los siglos XVI y XVII fueron los de mayor efervescencia constructiva, tal y como se refleja en la impronta que las fábricas renacentistas y barrocas dejaron en la morfología urbana (Fig. 1). ${ }^{7}$

En algunos grabados de la época se han reproducido los principales edificios de Palma en la Edad Moderna. La catedral, parroquias y conventos se destacan en el plano de una ciudad monumental constreñida por el cinturón de la fortificación. Las nuevas edificaciones, tanto civiles como religiosas, le dieron un aspecto renovado y moderno, a pesar de que se proyectaron sobre la trama medieval que apenas sufrió modificaciones.

A lo largo de esta etapa se instalaron en Palma tres conventos masculinos: San Francisco de Paula, Nuestra Señora de Monti-sión y el de la Concepción situado extramuros, además de otros siete de religiosas contemplativas: Nuestra

6 En las comunidades religiosas, y en concordancia con buena parte del territorio peninsular, observamos una preponderancia de franciscanos, agustinos y dominicos. Con respecto al norte de España, es notoria la escasa presencia en Mallorca de órdenes monásticas medievales de benedictinos y cistercienses, tan solo representadas por el convento cisterciense de Santa María la Real, situado a cierta distancia de la ciudad de Palma.

El Renacimiento en Mallorca comienza en la década de 1510 y ocupa prácticamente todo el siglo XVI. En el siglo XVII, la década de 1620 fue la que marcó la transición al Barroco, estilo que se prolongó hasta mediados de la centuria siguiente. La cronología establecida para Mallorca coincide, en líneas generales, con la establecida para los territorios de la monarquía hispánica.
FIGURA 1

\section{Vista de Palma (1779)}

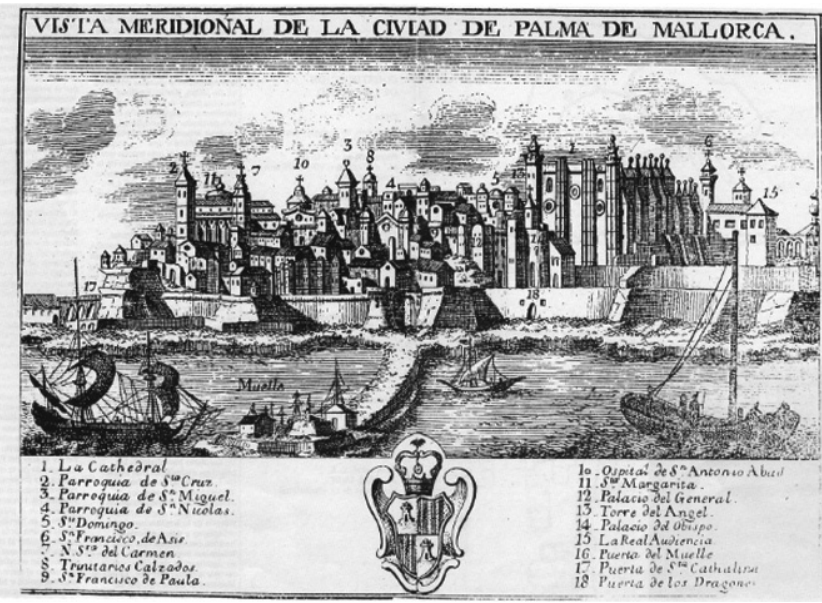

Fuente: Espinalt y Garcia, B. (1779). Atlante Español o descripción general Geográfica, Cronológica e Histórica de España por Reynos y Provincias. Tomo II, Mallorca. Madrid: imprenta de Antonio Fernández. P.250.

Señora del Olivar, Nuestra Señora de la Concepción, Nuestra Señora de la Misericordia, Nuestra Señora de la Consolación, Santa Teresa de Jesús, Santa Catalina de Sena y el de la Purísima Concepción. En los siglos XVII y XVIII hubo un total de veintisiete conventos, y además se renovaron muchos templos parroquiales (San Miguel, Santa Eulalia, San Nicolás y San Jaime) y conventuales (el Socorro, Santa Catalina de Sena, la Merced, San Felipe Neri, y la Concepción). Esta acelerada actividad contribuyó a fortalecer el carácter sagrado de la ciudad convento palmesana.

La localización de los edificios religiosos estuvo en gran parte determinada por dos actuaciones de gran trascendencia urbanística: la ampliación del perímetro de la muralla y el cambio de rumbo del torrente de la Riera.

\section{La fortificación de la ciudad}

La ciudad tuvo a lo largo de su historia cinco recintos amurallados. La primera cerca se levantó en la época romana y la última en el Renacimiento. La muralla se fue modificando y ampliando según fue creciendo la urbe y aumentando la preocupación por su defensa. Autores que han prestado atención especial a esta cuestión han sido Carlos García-Delgado (2000), Magdalena Riera (1993), Guillem Rosselló Bordoy (2007), Miquel Seguí Aznar (1990), Andreu Seguí Beltrán (2011) y Juan Tous (2004). ${ }^{8}$ La mayoría de los planos que se conservan de Palma fueron realizados con el objetivo de plasmar la evolución de la fortificación.

La presencia de la muralla influyó de manera decisiva en la localización de los conventos. Absolutamente todos los femeninos y la mayor parte de los masculinos se situaron bajo su amparo. Unos lo hicieron en sectores más periféricos (primeras fundaciones medievales) y otros en sectores centrales, al igual que también hubo algunos que se localizaron fuera de sus límites.

8 Estos autores han estudiado el urbanismo de la ciudad y formulado hipótesis sobre la superficie y los límites de cada uno de los cinco recintos fortificados que se levantaron en Palma en las diferentes etapas históricas. 
Los primeros claustros se ubicaron de manera paulatina en el interior del cuarto recinto, toda vez que la ciudad fue conquistada a los árabes en $1229 .{ }^{9}$ Poco a poco, la antigua Madina Mayurqa se fue cristianizando e incorporó funciones religiosas que convivieron con las residenciales, comerciales y artesanales, dando lugar a la aparición de áreas especializadas que contaron con sus iglesias y conventos. En la construcción de los claustros se emplearon artesanos, obreros especializados, maestros mayores e incluso, en alguna ocasión, participaron ingenieros de la fortificación. ${ }^{10}$

La muralla renacentista, conocida como el quinto recinto, fue la más extensa en superficie y la más robusta en su estructura, y también guareció a los nuevos cenobios que nacieron durante la etapa en que esta se levantó y que, en ocasiones, se posicionaron estratégicamente en las proximidades de sus puertas. El sistema defensivo se basó en la presencia de baluartes poligonales que recibieron el nombre de alguno de los conventos e iglesias de los alrededores: baluarte y puerta de Santa Margarita, baluarte de San Antonio, baluarte del Socorro, baluarte de San Jerónimo, etc.

En definitiva, la fortificación no solo constituyó un mecanismo simbólico de defensa de la ciudad sino también el elemento bajo el cual la mayoría de los conventos buscaron protección hasta el momento de su derribo a finales del siglo XIX. Muralla y conventos, al igual que sucedió en otras ciudades españolas, desaparecieron en una misma época bajo la justificación de un pretendido progreso vinculado a la caída del Antiguo Régimen, después de haber compartido largo tiempo juntos y de constituir una imagen indisoluble de ciudad en las etapas medieval y moderna.

\section{El desvío del torrente de la Riera}

Junto a la fortificación de la ciudad, la otra gran actuación urbana fue el desvío del cauce del torrente de la Riera hacia el foso de las nuevas murallas. Una obra decisiva para la urbe que tuvo lugar en 1613. Los autores María Barceló (2010), Carlos García-Delgado (2000), Juan Tous (2002) y Diego Zaforteza (1953), han estudiado las transformaciones operadas en la estructura urbana a consecuencia de esta importante intervención.

El torrente de la Riera atravesaba una amplia zona de Palma dividiéndola en dos partes, vila de baix y vila de dalt, para acabar desembocando en el mar. La decisión

9 Tras la conquista y, en contra de la creencia general, el perímetro urbano no fue modificado. La gran reserva de suelo sin edificar no hizo necesaria una ampliación de la muralla hasta que, en el siglo XV, se consideró la conveniencia de su renovación.

10 En Mallorca no hay arquitectos a quién se pueda atribuir la idea del diseño o trazado de los conventos ya que en este territorio no existió esta figura hasta el siglo XIX, cuando se reconoció la arquitectura como actividad profesional. En este contexto, únicamente tenemos constancia de la participación de algunos ingenieros de la fortificación que intervinieron de manera puntual bajo las órdenes de los maestros mayores en las obras de algún cenobio. Este fue el caso de Martín Gil de Gaínza, que coetáneamente trabajó en la fábrica de la muralla y en la iglesia del convento de la Purísima Concepción, a quién se atribuye su trazado (Novo 2016: 369). La mayor parte de las veces los trabajos de dirección de las obras conventuales fueron realizados de manera anónima por canteros o maestros mayores, cuyas figuras acumularon una gran experiencia técnica. Estos personajes fueron en realidad los verdaderos protagonistas de esta arquitectura conventual sin arquitectos, a los que dieron cobertura gran cantidad de artesanos especializados. de intervenir se tomó porque el espacio ocupado por sus márgenes se veía afectado periódicamente por el desbordamiento de las aguas y porque en la Edad Moderna en las ciudades españolas y europeas se experimentó un afán monumentalizador y de embellecimiento urbano tanto de espacios públicos como privados (Fernández Cuesta y Fernández Salinas 2010: 12). Por un lado, con este cambio de rumbo se corrigieron las deficiencias y se ampliaron los límites de la ciudad. Por otro, la urbanización del antiguo meandro generó nuevas centralidades y dotó a Palma de espacios libres y áreas de paseo que, a la postre, se demostraron importantes tanto para su imagen como para la comunicación entre la parte alta y la baja. El eje viario Rambla-Born se convirtió, desde entonces, en una de las principales arterias de tránsito de la ciudad y configuró uno de los espacios públicos de mayor envergadura: un lugar de esparcimiento, extroversión y encuentro social que, en el contexto urbano actual, todavía desempeña esta función.

La dimensión y el impacto de esta actuación urbana revalorizó considerablemente la zona y se dejó sentir en la presencia y orientación de los claustros. Tras las obras, se instalaron dos nuevos conventos, el de Santa Teresa (1617) y el de la Purísima Concepción (1662), y se desencadenaron cambios de orientación en el del Carmen y en el de Santa Magdalena, que anteriormente daban la espalda al torrente y ahora abrieron sus fachadas hacia el recién estrenado espacio público.

Una vez finalizados los trabajos de desvío del cauce de la Riera y de acondicionamiento de la zona, el sector RamblaBorn, que ya contaba con dos fundaciones medievales (Santa Magdalena y el Carmen), se vio enriquecido por la

FIGURA 2

Conventos situados en el eje de la Rambla

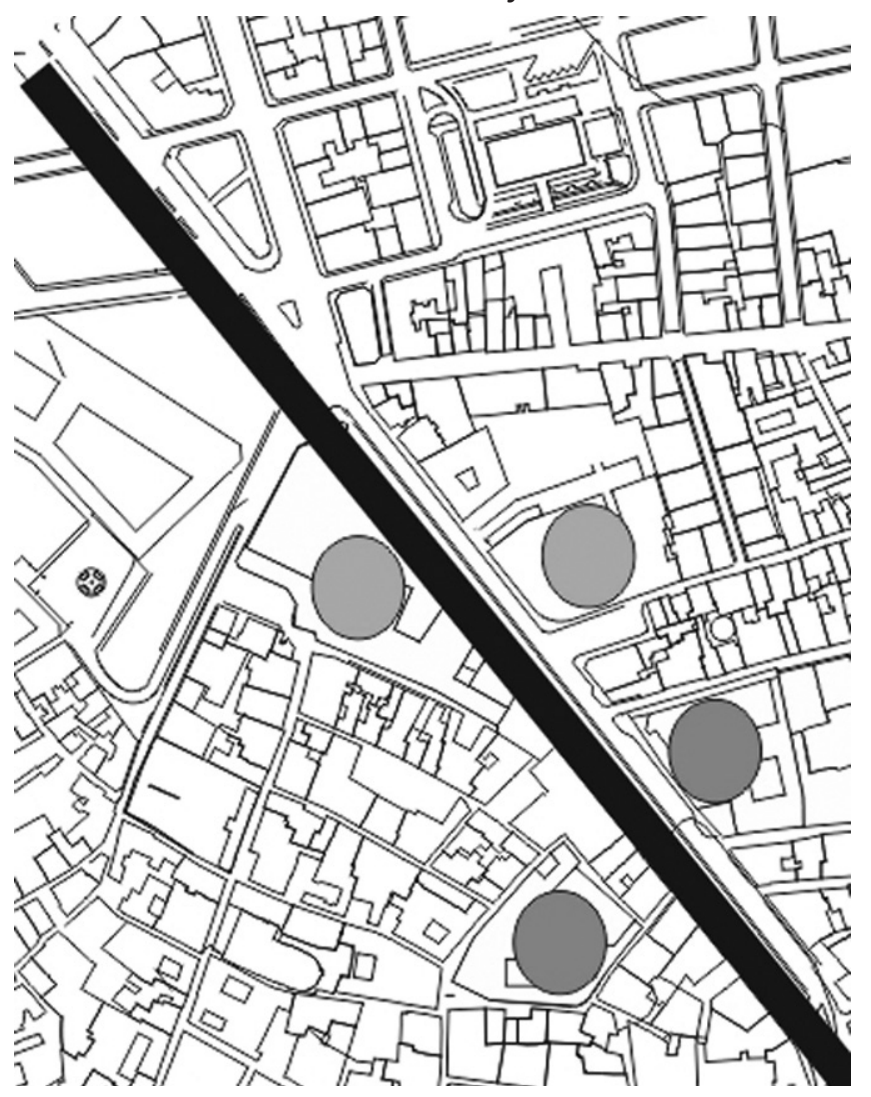

Fuente: elaboración propia. 


\section{FIGURA 3}

Localización de los conventos en la trama urbana del centro histórico de Palma según su etapa de fundación

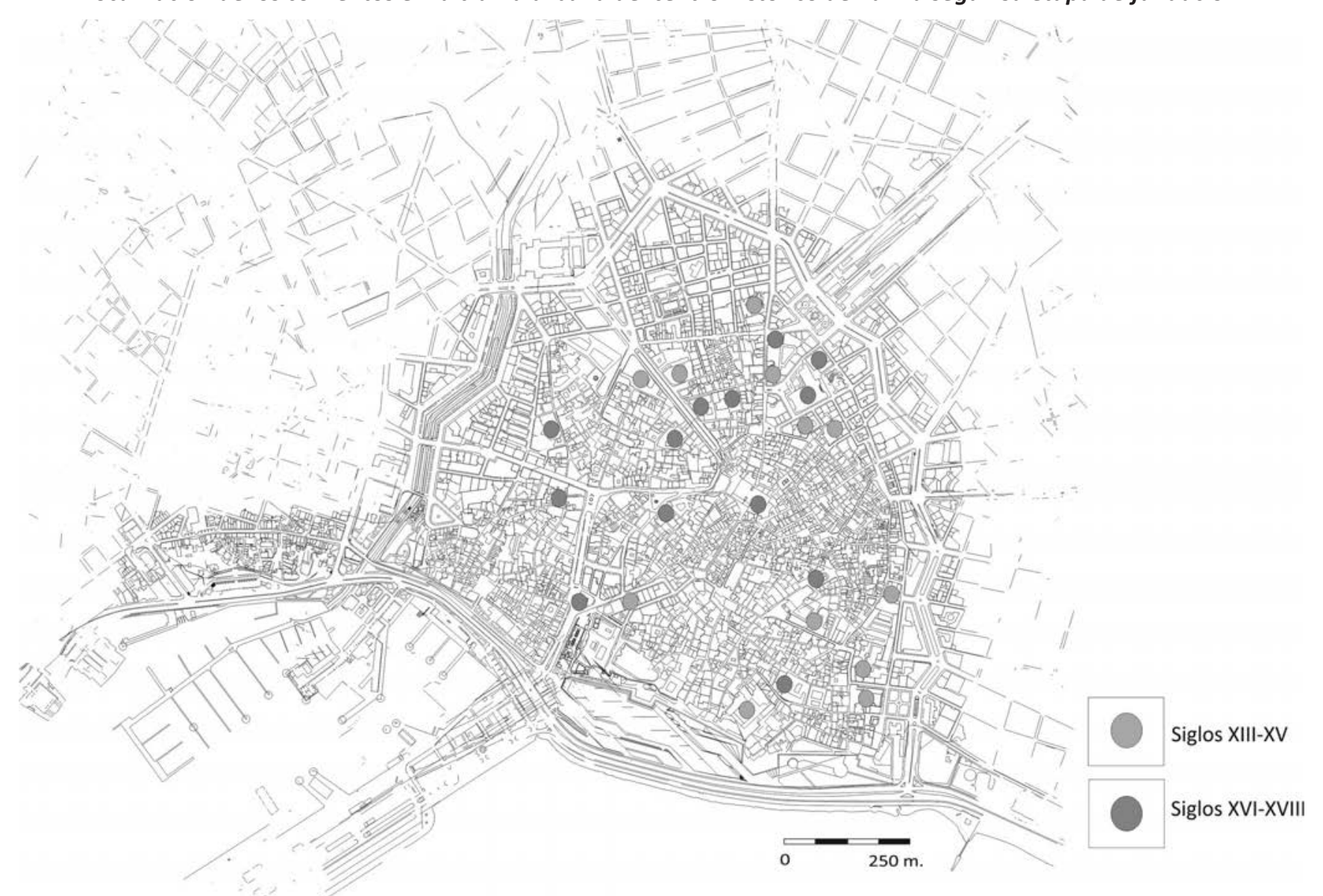

Fuente: elaboración propia.

construcción de dos nuevos conventos de clausura: Santa Teresa y la Purísima Concepción (Fig. 2). La relación de proximidad de estos cuatro cenobios que convivieron en esta zona a partir de la segunda mitad del siglo XVII, la hace merecedora de ser calificada como un archipiélago conventual.

\section{LA LOCALIZACIÓN DE LOS CONVENTOS}

El conocimiento del número y de la distribución espacial de los conventos es fundamental para entender el papel que han desempeñado y cuál fue su nivel de influencia en la morfología y estructura urbanas o en la recualificación de la ciudad. Además, no debemos olvidar que, en el pasado, un convento fue mucho más que una institución religiosa, ya que constituyeron grandes centros económicos y de poder cuya presencia también influyó en el peso que a nivel urbano tuvieron los barrios en donde se localizaron.

Tal y como sucedió en otras localidades, y en conexión con la idea expresada por Pérez Cano de que «no hay una regla o un hilo conductor estrictamente homogéneo que presida la implantación de los conventos en pos de una ciudad conventual con una modelística concreta», en Palma tampoco encontramos parámetros normativizados que determinen su ubicación definitiva (Pérez Cano 1996: 252). Además, en la época que nos ocupa tampoco se puede hablar de planes urbanísticos, ni de políticas que regulen su localización. ${ }^{11}$ Por tanto, su distribución en diferentes sectores de la ciudad parece haber sido producto de situaciones singulares, en principio no planificadas, probablemente en muchos casos derivadas de las donaciones efectuadas para su fundación o de los intereses señoriales que orientaron la elección de los lugares de asentamiento (Atienza 2009: 62). En Palma, no existen datos o fuentes que nos remitan a la existencia de una programación general aunque, sin embargo, determinadas cualidades observadas en la localización de los conventos, como son la proximidad a las puertas y a las plazas y su ubicación en los principales ejes de penetración hacia el interior del casco, nos hablan de cierto grado de racionalidad, de aproximación a una idea organizada de ciudad conventual.

En referencia al número de establecimientos hemos podido constatar que, entre los siglos XIII y XIX, llegó a haber treinta conventos pertenecientes a diferentes órdenes $y$ congregaciones religiosas, veinticinco de ellos en el actual centro histórico (Fig. 3). Entre los masculinos hubo mayor

11 En la mayoría de las ciudades españolas y europeas la localización más habitual a partir de la Edad Media fue en el núcleo urbano aunque también hubo conventos que se situaron fuera de las murallas, por lo general a poca distancia de alguna de las puertas de entrada de las urbes. La tendencia a ocupar lugares centrales continúa en las casas de vida activa creadas en los últimos años y que constituyen el relevo a los antiguos conventos. 
variedad: dos franciscanos, dos agustinos y una representación de templarios, mercedarios, dominicos, carmelitas, trinitarios, mínimos, jesuitas, paúles, teatinos y oratonianos. En los femeninos predominaron las congregaciones agustinas con cinco conventos, a los que se sumaron tres de franciscanas y uno de carmelitas, dominicas y jerónimas.

El estudio de la localización de los conventos palmesanos lo afrontamos a partir de tres perspectivas de análisis: proceso de implantación y distribución en la ciudad, causas, y uso y ocupación de los solares antes de su instalación (las preexistencias). ${ }^{12}$

Por lo que respecta a la distribución, en un primer momento y tras la conquista de Mallorca por los cristianos, el principal desafío consistió en ocupar el recinto amurallado, en donde también había grandes áreas sin urbanizar y amplias zonas dedicadas a huerto. ${ }^{13}$ En este contexto, la implantación conventual fue relativamente fácil ya que la propiedad del suelo aún estaba escasamente arraigada y había sectores de baja densidad poblacional y disponibilidad de edificios ganados en la conquista a los árabes. Las nuevas fundaciones se fueron asentando en un área reducida, pero ocupando diferentes partes. La mayoría descartaron el área extramuros por considerarla desestructurada e inhóspita, a pesar de que contaba con terrenos baratos aptos para el cultivo y ofrecía más posibilidades para la extensión. En definitiva, las instituciones conventuales medievales, tanto masculinas como femeninas, se instalaron en el interior de la urbe, tendencia que se acentuó a partir de la Contrarreforma, cuando además demostraron preferencia por ocupar lugares centrales o con algún valor estratégico.

En la Edad Moderna determinados sectores que habían sido ocupados con anterioridad por algún convento se vieron afectados por un proceso de densificación. La calle San Miquel, el barrio del Mercat o la zona de la Rambla a la altura del Pla del Carme son lugares en donde se aprecian estas dinámicas. Por un lado, el interés por situarse en un ámbito de poder podría explicar estas concentraciones que, en principio, eran contraproducentes por la competencia a la hora de recaudar limosnas. Por otro, el fuerte activismo religioso promovido en algunos claustros (caso de Santa Clara entre los femeninos o de Santo Domingo como promotor de los autos de fe de la Inquisición), puede ayudar a entender por qué persiguieron estas posiciones. Otra explicación que justifica en determinadas circunstancias la vecindad entre dos conventos está en la protección que los femeninos encontraban en los masculinos de la misma orden, como ocurrió con los de Santa Teresa y el Carmen, situados uno a continuación del otro en la Rambla y ambos pertenecientes a la orden carmelita.

Tal y como observamos en la tabla 1 los conventos se fueron ubicando en diferentes barrios, aunque claramente unos tuvieron más peso que otros, como sucedió en el área del Mercat. En la encrucijada compuesta por este barrio y los dos más próximos (Plaça dels Patins y la Missió) se

12 El proceso de implantación conventual en Palma ha sido estudiado por Rosselló Bordoy 2007 y Bordoy Bordoy 2009.

13 En el núcleo urbano de Palma se mantuvieron durante siglos algunas huertas de considerable dimensión que constituyeron la reserva urbana y que, probablemente, fueron herencia del viejo orden de la ciudad conventual.
TABLA 1

Localización de los conventos intramuros por zonas estadísticas del padrón municipal de habitantes (equivalente a la división por barrios)

\begin{tabular}{|l|l|}
\hline \multicolumn{1}{|c|}{$\begin{array}{c}\text { Zona estadística } \\
\text { (barrio) }\end{array}$} & \multicolumn{1}{c|}{ Convento } \\
\hline La Calatrava & Santa Clara \\
\hline Plaça dels Patins & Santa Margarita \\
\hline Monti-sión & Santa Elisabet, Monti-sión \\
\hline Sant Jaume & $\begin{array}{l}\text { Santa Magdalena, Nuestra Señora de la Concepción, } \\
\text { Purísima Concepción }\end{array}$ \\
\hline El Sindicat & $\begin{array}{l}\text { San Francisco de Asís, Nuestra Señora de la } \\
\text { Consolación*, El Temple, Nuestra Señora del Socorro }\end{array}$ \\
\hline El Mercat & $\begin{array}{l}\text { Nuestra Señora de la Merced, Santo Espíritu (actual San } \\
\text { Felipe Neri), San Antonio Abad, Santa Catalina de Sena, } \\
\text { Nuestra Señora del Olivar*, Purísima Concepción (los } \\
\text { Capuchinos) }\end{array}$ \\
\hline Sant Nicolau & $\begin{array}{l}\text { Santo Domingo*, San Francisco de Paula*, Nuestra } \\
\text { Señora de la Misericordia* }\end{array}$ \\
\hline La Llotja-Born & San Cayetano \\
\hline Cort & San Felipe Neri* \\
\hline La Missió & $\begin{array}{l}\text { Casa Misión de San Vicente de Paúl, Nuestra Señora del } \\
\text { Carmen*, Santa Teresa }\end{array}$ \\
\hline
\end{tabular}

Fuente: elaboración propia a partir de la distribución por barrios establecida por el Observatori Municipal de Palma.

localizaron diez, casi la mitad de los habidos en toda la ciudad. En el Sindicat también hubo una elevada concentración $y$, al igual que ocurrió en los demás distritos, convivieron fundaciones medievales con las pertenecientes a la Edad Moderna, y masculinas con femeninas. ${ }^{14}$ Los conventos más cercanos, salvo excepciones como el del Carmen y Santa Teresa, no pertenecieron a la misma orden y además, casi siempre, la llegada de una nueva comunidad fue motivo de conflicto ya que, por norma, los claustros ya asentados se oponían a compartir su espacio con una nueva fundación. ${ }^{15}$ Esta conflictividad, que jalonó muchos de los procesos fundacionales en Palma, es un indicador de que estos centros fueron mucho más que meros centros de vida religiosa, a quien costaba compartir su parcela de autoridad. Las causas de esta oposición hay que buscarlas tanto en los intereses de índole económico como en el hecho de que los nuevos conventos conllevaban una gran capacidad de intervención en las tramas de poder locales (Atienza 2008: 452).

Los cenobios situados extramuros fueron cinco, o siete si contabilizamos los tres agustinos que existieron en la zona de Itria. Con respecto a las cifras totales su número es reducido, por lo que resulta obvio que la cultura monacal en

14 Los conventos cuyo nombre se acompaña de un asterisco han desaparecido en su totalidad, es decir, no se ha mantenido ni siquiera el espacio de la iglesia. Entre los que permanecen, el de San Antonio Abad y el del Temple no están activos como conventos.

15 Entre los conventos masculinos fue especialmente polémica la fundación de San Francisco de Paula (1585) que tuvo que hacer frente a la gran presión inicial que ejerció el convento de Santo Domingo (1231), que se posicionó radicalmente en contra de su instalación. El cenobio dominico estaba ubicado en las proximidades de la primera casa adquirida por los mínimos en la parroquia de San Nicolás. La crónica de la controversia y el relato de la fundación se puede consultar en la obra de P. Frau Nicolau 1709. 
Palma durante los períodos medieval y moderno tuvo una clara vocación urbana, más acusada incluso en los conventos femeninos. No obstante, entendemos que esta localización más alejada de los límites de la ciudad es un indicador de la proyección de las órdenes religiosas fuera del marco propiamente urbano.

Los claustros que estuvieron fuera del perímetro de las murallas fueron el franciscano de Jesús extramuros, el capuchino de la Concepción, el trinitario de Santa Catalina y los agustinos de Itria (Tabla 2). ${ }^{16}$ Todos se ubicaron en un radio bastante próximo a los límites de la cerca dado que su principal elemento de referencia era la ciudad que, además, constituía la razón de ser de su existencia. En la actualidad, estas zonas se han integrado en barrios del núcleo urbano de Palma. Más alejado, y en una posición de aislamiento con respecto al centro de la urbe, estaba el monasterio cisterciense de Santa María la Real, en una vía de salida de la ciudad y a varios kilómetros de los núcleos poblados.

TABLA 2

Localización de los principales conventos extramuros por zonas estadísticas del padrón municipal de habitantes (equivalente a la división por barrios)

\begin{tabular}{|l|l|}
\hline \multicolumn{1}{|c|}{$\begin{array}{c}\text { Zona estadística } \\
\text { (barrio) }\end{array}$} & \multicolumn{1}{c|}{ Convento } \\
\hline Bons Aires & Convento capuchino de la Concepción \\
\hline Camp Redó & Convento de Jesús Extramuros \\
\hline Secar de la Real & Monasterio de Santa María de la Real \\
\hline Santa Catalina & Convento de la Trinidad \\
\hline Arxiduc & Convento de Itria \\
\hline
\end{tabular}

Fuente: elaboración propia a partir de la distribución por barrios establecida por el Observatori Municipal de Palma.

La realidad más compleja es la que corresponde al monasterio agustino de Itria. ${ }^{17} \mathrm{Su}$ historia ha sido caracterizada por Mercè Gambús como la historia de la tenacidad debido a que «tres veces fue construido y otras tantas derruido» (Gambús 1981: 305). La causa principal de sus destrucciones consecutivas se relaciona con la defensa de la ciudad, pues los cambios en el emplazamiento de la fortificación obligaron al derribo sucesivo de la fábrica conventual. La cronología de su existencia, no obstante, es amplia ya que abarca desde 1480, fecha de la primera fundación, hasta 1771 cuando desapareció el último convento.

Las causas que explican la ubicación de los conventos en los distintos sectores de la ciudad son variadas y diversas. Un factor determinante es el que se relaciona con la obtención de solares y casas donde establecer a los religiosos o religiosas y efectuar la fundación. En este sentido, los métodos más comunes para conseguir la propiedad fueron las donaciones de inmuebles o terrenos, las adquisiciones por la propia orden y las concesiones por parte de las autoridades. En ocasiones, las dádivas de las clases privilegiadas

16 En el área extramuros también se localizaron dos centros asistenciales: el hospital de Santa Catalina y el de los leprosos. A excepción del de Santa María la Real, todos los conventos y hospitales han desaparecido.

17 Véase Bóver 1860. también permitieron a las comunidades religiosas comprar casas o terrenos circundantes al convento.

Al comienzo de la Edad Media muchos de los claustros palmesanos van a surgir al amparo de las donaciones reales (Santo Domingo, Nuestra Señora de la Merced, el Temple...). Más adelante, en la Edad Moderna, y principalmente en relación con los conventos de religiosas, la mayor parte de las donaciones fueron realizadas por familias nobles y acaudaladas de la ciudad que, o bien cedieron alguna de sus propiedades para este fin, o bien dieron donativos a las monjas para que pudieran comprar las casas en donde establecerse (circunstancia de la familia Ortiz con respecto al convento de Santa Teresa o de don Joan Baptista Despuig responsable de la fundación de Santa Catalina de Sena). Otras veces, estas mismas familias se hicieron cargo de las obras de construcción o acondicionamiento de los cenobios. Por su parte, hubo también casos, como el del convento de San Francisco de Paula, en donde la primera propiedad fue adquirida por la propia orden, o de congregaciones que contaron con el apoyo de instancias municipales, como aconteció con los jesuitas.

Los inmuebles sobre los que se efectuaron las fundaciones o las posteriores anexiones constituyen las preexistencias, por lo general conjuntos de casas que fueron cedidas en propiedad a las órdenes y que se fueron transformando en función de los medios económicos y de las necesidades monásticas. No obstante, su análisis resulta complicado ya que, en Palma, la información sobre los usos o el tipo de ocupación previa a la construcción de los conventos es muy escasa y, a lo sumo, nos encontramos con alguna pequeña alusión a su primitiva función (caso de la jabonería árabe sobre la que se fundó el convento de Santa Margarita o de los baños de esta misma época con respecto al de Santa Clara) o con los nombres de los antiguos propietarios. Lo que sí sabemos es que, por norma, los núcleos iniciales conventuales no fueron muy grandes y la tendencia fue que, a medida que las comunidades iban creciendo, fueron adquiriendo o anexionando propiedades de las inmediaciones, muchas de las cuales eran de pequeña entidad y estructura irregular. Estas nuevas incorporaciones nos remiten a una arquitectura personalizada y edificada lentamente, sin apenas planificación previa y sin participación de arquitectos, con una impronta doméstica importante derivada de la anexión continuada de diferentes casas. ${ }^{18}$ Los restos de estas edificaciones primitivas todavía se pueden apreciar en un buen número de los conventos de Palma (Figs. 4 y 5).

En algunos conventos como el de Santa Elisabet, la absorción no se limitó únicamente a las casas, sino que también se incorporaron fragmentos del viario urbano. Este monasterio integró calles de origen medieval que nos remiten a un pasado lejano que ha quedado atrapado entre sus muros. Otros cenobios, como el de Santa Clara o el antiguo convento de Santa Margarita, constituyen magníficos ejemplos de arquitectura doméstica bajomedieval donde todavía se mantienen visibles restos heredados del pasado musulmán.

18 Esta domesticidad es más visible en los claustros femeninos. Los conventos masculinos impulsados por la realeza estuvieron dotados desde el origen de espacios más amplios (solares o inmuebles), razón que explica que no hayan tenido la misma necesidad de aumentar la superficie conventual y no hayan incorporado en sus estructuras originales tantas casas como en el caso de los conventos de religiosas. 
FIGURA 4
Arcos de época musulmana en el exconvento de Santa Margarita

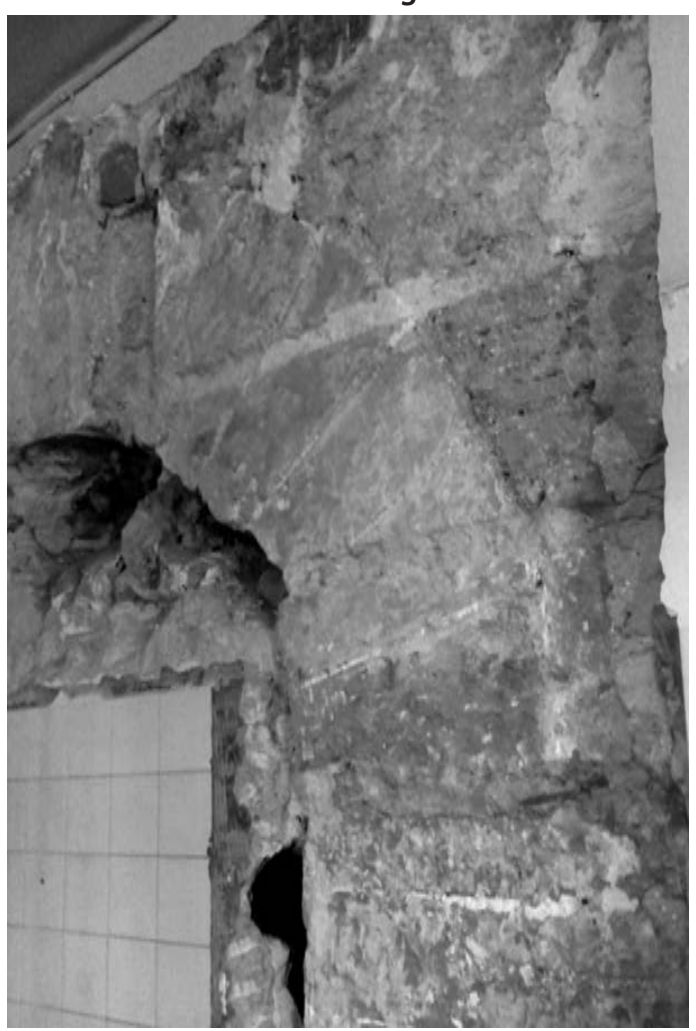

Fuente: elaboración propia.

FIGURA 5

Restos de antigua casa gótica en el convento de la Concepción

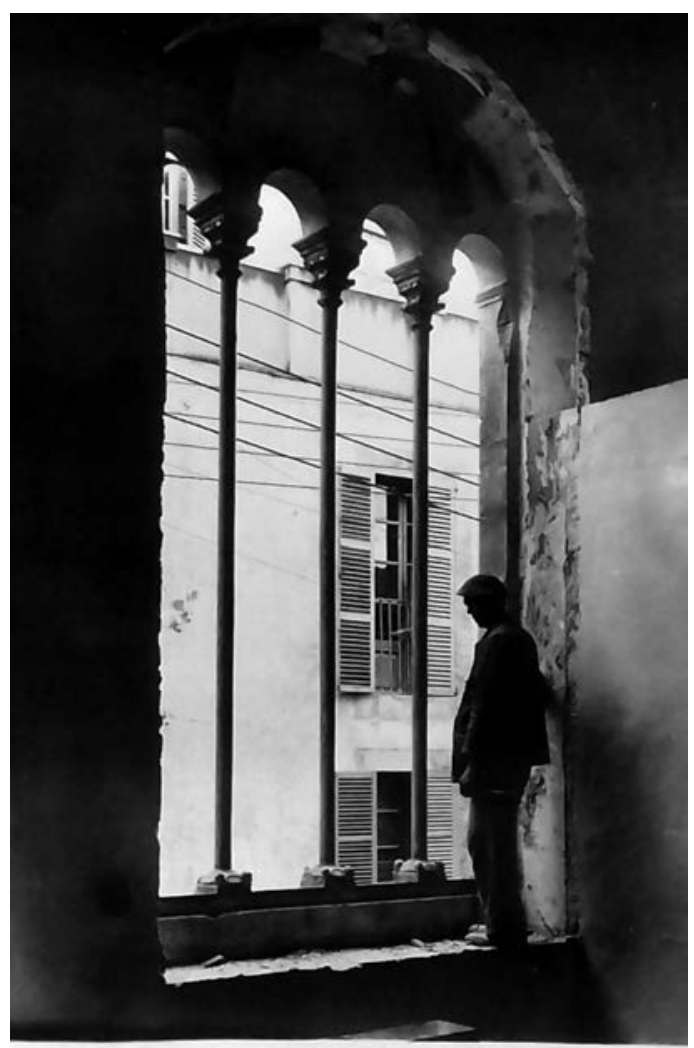

Fuente: Fondo Biblioteca Luis Alemany.
UNA APROXIMACIÓN AL MAPA CONVENTUAL PALMESANO: LOS ARCHIPIÉLAGOS CONVENTUALES

La morfología urbana de Palma ha estado determinada por el importante número de instituciones conventuales que ha tenido. Su distribución en el plano de la ciudad nos ha permitido delimitar zonas de elevada concentración que hemos definido como archipiélagos conventuales. La posición de estos archipiélagos con frecuencia se relaciona con los principales ejes estructurales o de penetración hacia el interior del casco que parten de las puertas de la muralla y conforman líneas conventuales.

En Palma, al igual que en el resto de las ciudades amuralladas, las puertas fueron destacados puntos estratégicos, lugares de entrada y salida a la urbe muy transitados por naturales y foráneos, en donde a los conventos resultaba más fácil obtener limosnas y ejercer el apostolado. Por tal motivo, hubo varios claustros que se localizaron en sus proximidades desempeñando también una función de guardas de la ciudad (convento de Santa Magdalena-puerta de Jesús, convento de Santa Catalina de Sena-puerta Pintada, convento de Santa Elisabet-puerta del Campo, etc.). Una dinámica que también se produjo a la inversa cuando en el quinto recinto fortificado se programaron nuevas aperturas de puertas en las inmediaciones de algún cenobio, del que tomaron incluso su nombre (puerta de Santa Margaritaconvento de Santa Margarita).

La fortificación renacentista contó con ocho puertas de acceso a la ciudad. Entre ellas y, por su situación privilegiada, destacaron la Puerta de Santa Margarita o Puerta Pintada (Fig. 6), muy vinculada con los conventos de Santa Margarita, Santa Catalina de Sena, y el capuchino de la Concepción; la Puerta de Jesús, relacionada con el convento de Santa Magdalena hacia el interior y con el de Jesús extramuros al exterior; y la Puerta del Campo, próxima al monasterio de Santa Elisabet y no muy alejada del Temple y Nuestra Señora del Socorro por un costado, y del de Santa Clara y Monti-sión por el otro.

En el plano de la figura 7 se representa el baluarte de Santa Margarita que da paso a la Puerta Pintada, también conocida como Puerta de Santa Margarita (Fig. 8). El convento de Santa Margarita fue uno de los que disfrutó de las ventajas de estar situado en las proximidades de tan cualificado punto de acceso de a la ciudad.

\section{FIGURA 6}

Puerta de Santa Margarita o Puerta Pintada y convento de la Purísima Concepción (Capuchinos)

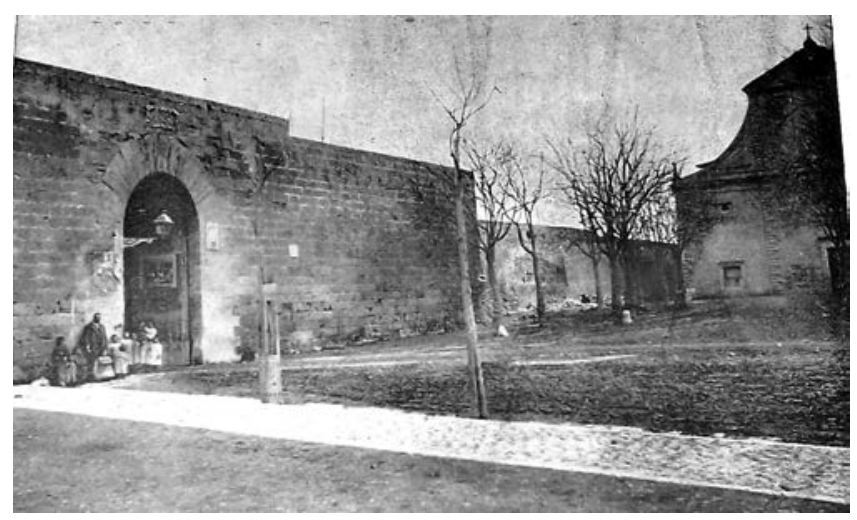

Fuente: Fondo Biblioteca Lluís Alemany. 
FIGURA 7

Plano manuscrito coloreado del baluarte de Santa Margarita con sus contornos (puerta y convento) realizado por Martín Gil de Gaínza (1728)

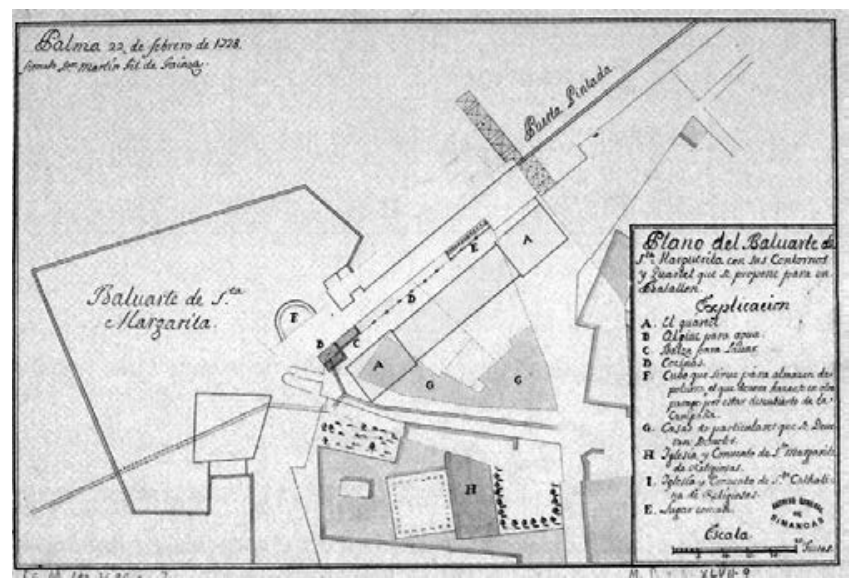

Fuente: Tous Melià, Juan (2002, 93).

Una estrategia habitual fue la de situar a los conventos en los principales ejes de penetración hacia el interior del casco urbano que, por lo general, partían de las puertas a las que hemos hecho referencia. De este modo, en un intento
FIGURA 8

Puerta de Santa Margarita

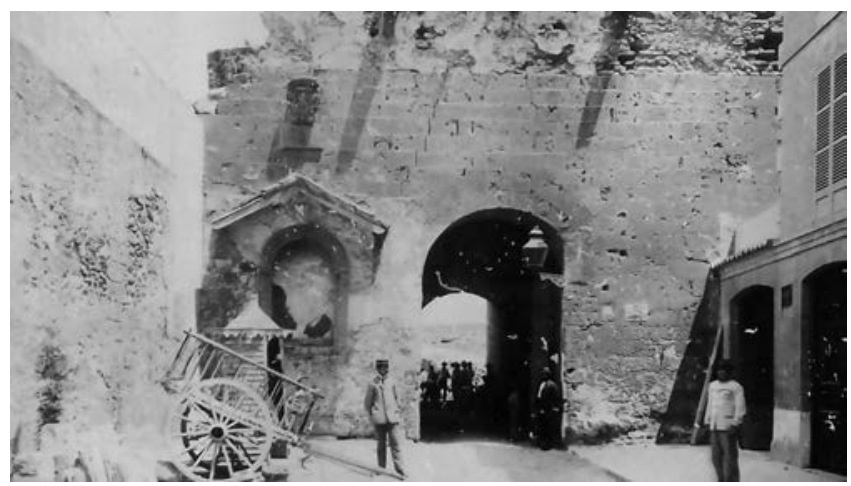

Fuente: Fondo Biblioteca Lluís Alemany.

de asumir posiciones de preeminencia y centralidad, se fueron concentrando en las vías más activas e importantes de Palma. Esta conexión puerta-eje va a marcar la configuración de los principales archipiélagos conventuales de la ciudad.

En nuestro análisis hemos detectado varios ejes cuya estructura se basa en la secuencia continuada de edificios conventuales (Fig. 9). Son los siguientes:

FIGURA 9

Principales ejes de penetración y localización de los conventos según siglo de fundación

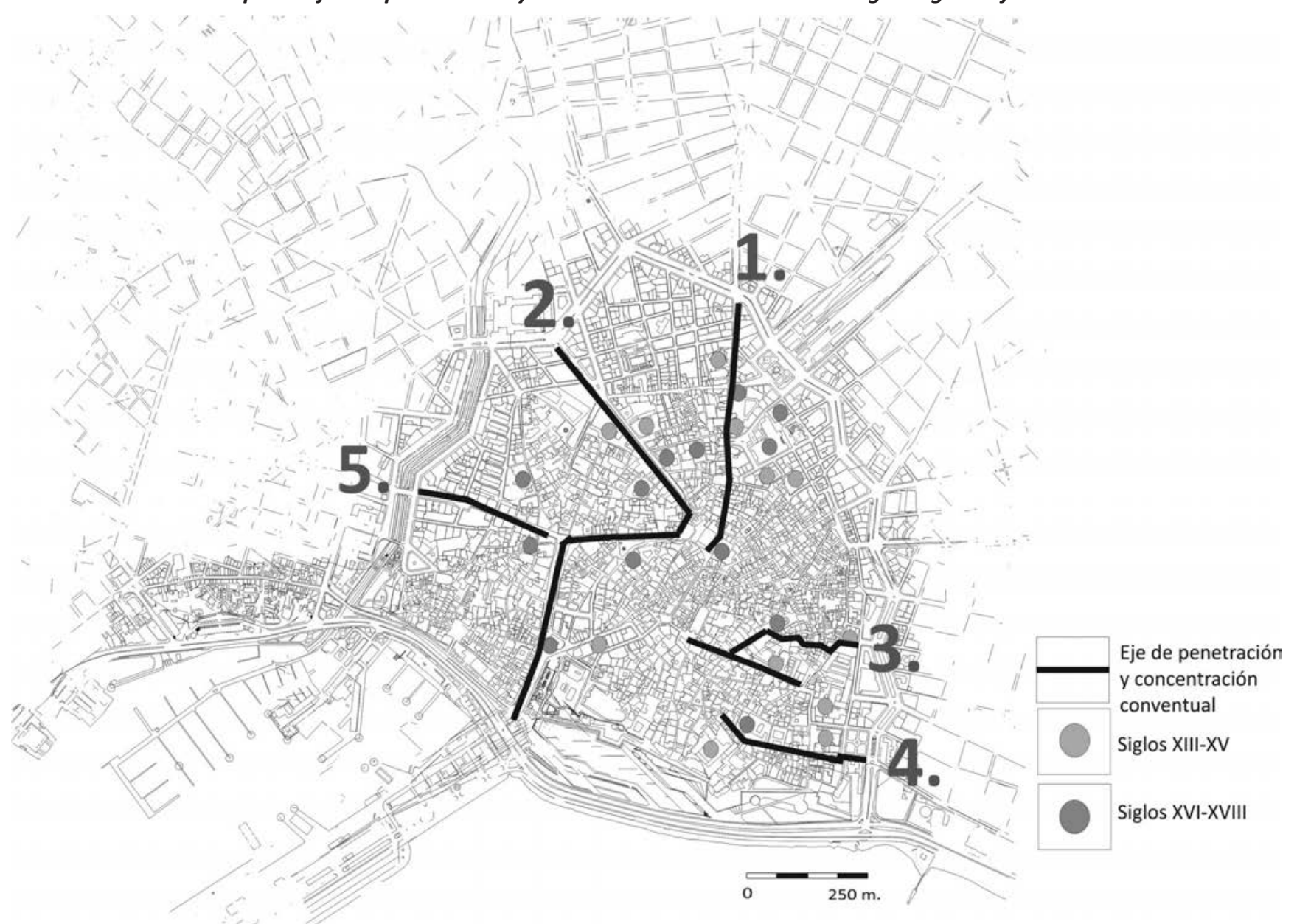

Fuente: elaboración propia. 
1. Eje que partía de la Puerta de Santa Margarita o Puerta Pintada y discurría por la calle San Miquel hasta llegar a la plaza Mayor. Su trazado constituyó una espina dorsal que unió a los conventos de Santa Margarita, Santa Catalina de Sena, San Antonio Abad y San Felipe Neri. Hacia la mitad de la calle San Miquel, en el barrio del Mercat, se ubicaron otros importantes cenobios: el capuchino de la Concepción, Nuestra Señora del Olivar, Santo Espíritu y Nuestra Señora de la Merced, por un lado, y la Casa Misión de San Vicente de Paúl, por el otro. Todos estos claustros constituyeron el más potente archipiélago conventual de Palma.

2. Eje que partía de la puerta de Jesús y atravesaba parte de la Rambla continuando por el Born hasta llegar al mar. En este tramo, ocupando diversos frentes de la vía Rambla-Born, se encontraban los conventos de Santa Magdalena, el Carmen, Santa Teresa, la Purísima Concepción, Nuestra Señora de la Misericordia y San Francisco de Paula, formalizando una gran línea conventual. Por razones de cercanía, hemos incluido también en este eje al convento de Santo Domingo, localizado a poca distancia de San Francisco de Paula.

3. Eje que tuvo como punto de inicio la parroquia de Santa Eulalia y en cuyo discurrir se ubicaron los conventos de San Francisco de Asís, Nuestra Señora de la
Consolación y el Temple. En él hemos incluido también al de Nuestra Señora del Socorro, aunque por cuestión de proximidad este cenobio y el del Temple pudieron haber formado un eje alternativo junto al monasterio de Santa Elisabet.

4. Eje que partía de la Puerta del Campo, del convento de Santa Elisabet, y continuaba por el barrio de la Calatrava incorporando a los de Santa Clara y Monti-sión.

5. Eje estructural en el que se localizaron solo dos claustros que estaban en una situación aislada con respecto al resto: San Cayetano, situado en un lateral de la actual calle Jaume III, y la Concepción, situado al otro lado de esta vía. Estos conventos, aunque estuvieron en una posición más discreta y apartada, colaboraron en la densificación de la ciudad conventual y contribuyeron a la sacralización de este sector urbano.

La mayoría de los conventos palmesanos se situaron en el recorrido de alguno de estos ejes y orientaron sus fachadas hacia las calles principales, como San Miquel o la Rambla-Born. Las fundaciones medievales, ocuparon con mayor frecuencia las zonas limítrofes, distribuyéndose por los contornos de la urbe desde donde abrieron ejes conventuales que partían hacia el centro. La posición de centralidad fue más codiciada por las fundaciones de la Edad Moderna. En fiestas extraordinarias las iglesias de estos conventos

FIGURA 10

Principales áreas de concentración conventual (archipiélagos) y localización de los conventos según el siglo de fundación

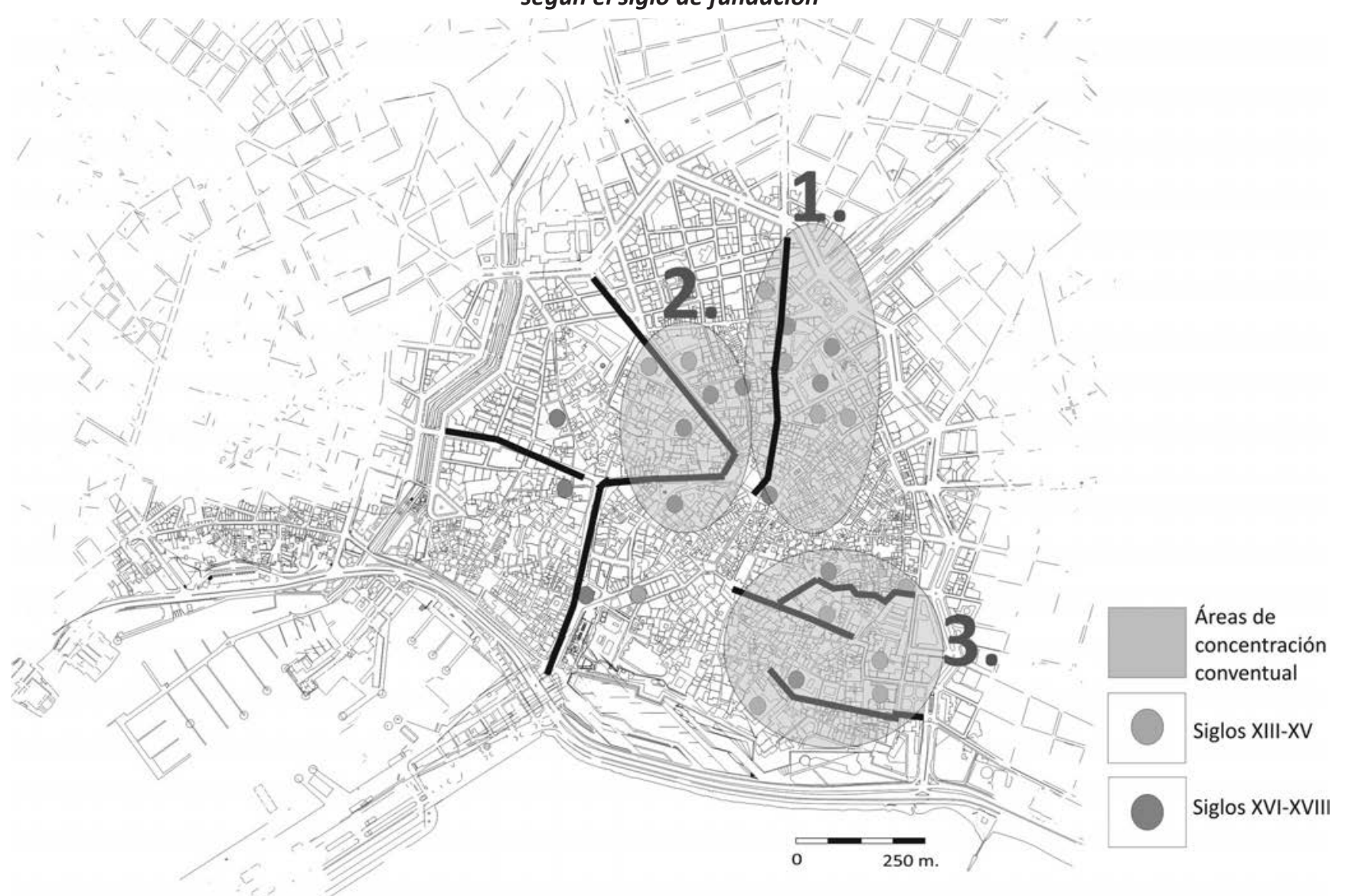

Fuente: elaboración propia.

Hispania Sacra, LXXI

143, enero-junio 2019, 259-270, ISSN: 0018-215X, https://doi.org/10.3989/hs.2019.019 
fueron puntos destacados del recorrido de las procesiones que discurrían por estos ejes.

Las fuentes cartográficas generadas a partir del siglo XVII reflejan como algunos ejes se fueron densificando y como en determinadas áreas de Palma las secuencias conventuales se hicieron continuas, aunque siempre manteniendo una distancia prudencial que protegía el aislamiento reclamado por estas instituciones. En este sentido, son especialmente significativos tres sectores que conformaron los archipiélagos conventuales más potentes de la ciudad (Fig. 10). Estos son los siguientes:

1. El archipiélago de la calle San Miquel y barrio del Mercat estructurado en el noreste de la ciudad, en el entorno de la actual plaza del Olivar. Aquí se localizaron los conventos de Santa Margarita, Santa Catalina de Sena, San Antonio Abad, Nuestra Señora del Olivar, Santo Espíritu, Nuestra Señora de la Merced, el capuchino de la Concepción y, en un radio un poco más distante, el de San Felipe Neri.

2. El archipiélago que emerge en las proximidades de la Rambla. En él estaban los cenobios de Santa Magdalena, la Purísima Concepción, el Carmen, Santa Teresa, la Casa Misión de San Vicente de Paul y un poco más alejado, el de Nuestra Señora de la Misericordia. En la actualidad todavía podemos hablar de archipiélago conventual, ya que aquí se concentran tres de las cuatro clausuras femeninas activas actualmente en Palma: Santa Teresa, Santa Magdalena y la Purísima Concepción.

3. El archipiélago localizado en el sureste de la ciudad, en la zona de Santa Eulalia-La Calatrava. En él se incluyeron los conventos de San Francisco de Asís, Nuestra Señora de la Consolación, Nuestra Señora del Socorro, el Temple, Santa Elisabet, Nuestra Señora de Monti-sión y Santa Clara.

La densificación de estos archipiélagos es un indicador de la capacidad que tuvieron las órdenes religiosas de poblar grandes sectores de la ciudad. El número de conventos establecidos, la monumentalidad de sus edificios y la preponderancia urbana que tuvieron estas instituciones nos indica que Palma, durante la Edad Media pero principalmente en la Edad Moderna, es una ciudad que se significa con la presencia conventual.

\section{CONCLUSIONES}

Los conventos participaron en el proceso colectivo de construcción de la ciudad de Palma a lo largo de siete siglos. Estas instituciones fueron responsables de importantes transformaciones urbanas: ocupación de vacíos urbanos, creación de nuevos barrios que surgen bajo su sombra, configuración de áreas muy pobladas y de fuerte densificación conventual, etc. Esta etapa se desarrolló desde 1229, año de la conquista de Mallorca por Jaime I, hasta el siglo XIX cuando la ciudad conventual entró en crisis y paulatinamente fue sustituida por un nuevo modelo de ciudad burguesa propia de la industrialización y de un nuevo régimen liberal.

Bajo la idea de convertir Palma en una ciudad cristiana, en la Edad Media los conventos fueron utilizados como instrumentos evangelizadores. Primero, para suprimir los antiguos vestigios de la ciudad musulmana, y después para relegar a la comunidad judía, recluida en la judería mayor (Call Major) por la presión ejercida, precisamente, desde las instituciones conventuales. En la Edad Moderna se multiplicaron las fundaciones. Al igual que sucedió en otras ciudades españolas, este es el momento en el que conviven un mayor número de conventos, hasta un máximo de veintisiete en el siglo XVIII, distribuidos por diferentes partes de la ciudad. Si tenemos en cuenta que durante estos siglos las ciudades se medían por el número de establecimientos religiosos, Palma se puede catalogar como una importante ciudad-convento por encima de otras urbes importantes como Girona, Cuenca, Málaga, Murcia, Burgos, Segovia, Jerez de la Frontera, Écija o Tarragona.

En todas las etapas estudiadas los conventos se entienden como un elemento claramente urbano. De un total de treinta cenobios fundados en Palma, veinticinco se situaron en la antigua ciudad intramuros. Dentro de ella, la localización estaba condicionada por diferentes factores, entre los cuales destacan la disponibilidad de espacio y la posibilidad de adquirir solares o inmuebles derivados de las donaciones. A estas se añade la influencia ejercida por dos grandes intervenciones urbanas del siglo XVII (la ampliación de la muralla y la desviación del rumbo del torrente de la Riera) en las últimas fundaciones. Las puertas de la fortificación constituyeron un punto de partida de ejes estructurales que conformaron líneas conventuales que discurrieron hacia el interior del casco. En su trayectoria se crearon áreas muy densificadas que dieron lugar a importantes archipiélagos conventuales, entre los que destacan los delimitados al noreste y sureste de la ciudad antigua.

La presencia conventual aumentó el valor de los barrios y contribuyó a transformar su fisonomía. Por un lado, la monumentalidad de los inmuebles los convirtió en hitos urbanos, claramente identificados en el paisaje de la ciudad. Por otro, las disposiciones que se dictaron para proteger la intimidad de estos centros, fundamentalmente en el caso de las clausuras, impusieron obligaciones constructivas determinantes para las calles y el caserío que circundaban estos edificios religiosos. Así, en los barrios con mayor concentración de conventos (la Calatrava, el Mercat, la Rambla-Born...) todavía se puede apreciar como una parte importante del caserío no supera la altura de los muros de los cenobios circundantes.

Por lo tanto, aunque la mayoría de los claustros ya no están activos con la función propiamente monástica, la herencia de la ciudad conventual se manifiesta con fuerza tanto en el legado artístico y monumental como en el proceso de urbanización y dibujo del mapa de la ciudad. En la actualidad, se conservan dieciséis conventos: diez de religiosos y seis de monjas, de los cuales cuatro son de clausura (Santa Teresa, Santa Magdalena, la Purísima Concepción y Santa Clara). Los femeninos son de mayores dimensiones, y aunque tienen un estado de conservación desigual, en general, están poco transformados manteniendo sus núcleos conventuales de manera bastante íntegra. La continuidad de uso durante casi toda su historia y el conservadurismo que caracterizó a las comunidades que los ocuparon ha favorecido el escaso nivel de transformación de los edificios. Por su parte, los masculinos han alterado en mayor medida sus formas originales, sobre todo a través de derribos parciales o cambios de usos. Las causas principales fueron las segregaciones 
realizadas por la autoridad civil en periodos de exclaustración. Aquellos cenobios enajenados que no fueron derribados sufrieron una gran reconversión, y de los antiguos recintos lo más respetado ha sido el edificio de la iglesia.

En definitiva, los conventos han demostrado ser elementos fundamentales en el proceso de urbanización de Palma, a pesar de que hoy en día se contemplan, casi exclusivamente, como elementos que contribuyen a la monumentalidad del centro histórico palmesano. Después de décadas de estabilidad, se adivinan años convulsos y cambios asociados a dos fenómenos principales, uno puramente religioso y otro económico. Por un lado, la crisis vocacional que padecen y la pujanza que, desde comienzos del siglo $\mathrm{XX}$, han tenido en Mallorca las nuevas congregaciones de votos simples (Hijas de la Misericordia, Hermanas de la Caridad...). Estas constituyen en la actualidad la mayoría del clero regular de la Iglesia y de las comunidades de Palma. Por otro, la intensa turistización que está conociendo el centro histórico de Palma sitúa en el centro del debate al probablemente único patrimonio que no ha entrado en el mercado turístico: los conventos. Las posibilidades de explotación turística de estos edificios son múltiples, pero por encima de todo destacan las presiones que están recibiendo para introducir el uso hotelero en algunos de ellos, a semejanza de lo experimentado en otras importantes arquitecturas del patrimonio civil del casco histórico de Palma.

\section{Bibliografía}

Atienza López, A. 2008. Tiempos de conventos. Una historia social de las fundaciones en la España Moderna. Madrid: Marcial Pons ediciones de Historia y Universidad de La Rioja.

Atienza López, A. 2009. "Nuevas consideraciones sobre la geografía y la presencia conventual en la España Moderna. Otras facetas más allá de la consideración urbana». Hispania Sacra 123: 51-75. https://doi.org/10.3989/hs.2009.v61.i123.79

Barceló i Crespí, M. 1985. «La ciudad de Mallorca en el último cuarto del siglo XV: parroquias y red viaria». España medieval 7: 1321-1332.

Barceló i Crespí, M. 2010. «Configuració urbana de la Ciutat de Mallorca medieval», en T. Sabater y E. Carrero Santamaría (coords.), XXVIII Jornades d'Estudis Històrics Locals: Palma, del 3 al 5 de novembre de 2009: 13-25. Palma de Mallorca: Institut d'Estudis Baleàrics.

Barceló i Crespí, M. y Moll Blanes, I. (coords.) 2004. Abadies, cartoixes, convents i monestirs. Aspectes demogràfics, socioeconòmics culturals de les comunitats religioses (segles XIII al XIX). Palma: Institut d'Estudis Baleàrics.

Barrio Gozalo, M. 1995. Segovia, ciudad conventual: El clero regular al final del antiguo régimen (1768-1836). Valladolid: Secretariado de Publicaciones de la Universidad de Valladolid.

Bernat i Roca, M. 2010. «De mâdina a urbs gótica: Ciutat de Mallorca, 1230-1300», en T. Sabater y E. Carrero (coords.), La Ciutat de Mallorca i els segles del gòtic: XXVIII Jornades d'Estudis Històrics Locals: 115-148. Palma: Institut d'Estudis Baleàrics.

Bordoy Bordoy, M. J. 2009. Arran de la Porta Pintada. Poder i prestigi femení al Monastir de Santa Margalida (Ciutat de Mallorca, segles XIII-XVI). Palma: Lleonard Muntaner Editor.

Bóver, J. M. 1860. "Convento de Itria», en Miscelánea Histórica Mayoricense. Palma Ms. Vol. XVIII, fols. 225 a 230 (Tomos manuscritos).

De Quiroga Conrado, M. M. 2014. Santa Margalida de Palma, de monasterio agustino a hospital militar siglos XIII-XX. Madrid: Ministerio de Defensa.

Espinalt y Garcia, B. 1779. Atlante Español o descripción general Geográfica, Cronológica e Histórica de España por Reynos y Provincias. Tomo II, Mallorca. Madrid: imprenta de Antonio Fernández.
Estelrich Costa, J. 2002. El Monastir de Santa Elisabet de Ciutat de Mallorca. Beguins, terceroles, jerònimes (1317-2000). Palma: Edicions Documenta Balear.

Fernández Cuesta, G. y Fernández Salinas, V. 2010. «La ciudad preindustrial», en G. Fernández Cuesta y F. Quirós (dirs.), Atlas temático de España: 9-84. Oviedo: Ediciones Nobel.

Frau Nicolau, P. 1709. Crónica de los conventos de la provincia de Mallorca de la orden mínima, transcripción realizada por $\mathrm{P}$. Florencio Rodríguez. Estudios Mínimos: 1-118.

Gambús Sáiz, M. 1981. «Aproximación a un estudio histórico-artístico del convento agustino de Itria». Separata del Bolletí de la Societat Arqueològica Lul-liana 835: 301-306, T. XXXVIII, any XCVII.

Gambús Sáiz, M. 1997. Una escenografía luliana en la antigua librería del Colegio de Montesión. Palma: Museu de Mallorca.

García-Delgado Segués, C. 2000. Las raíces de Palma: los mil primeros años de la construcción de una ciudad. De la colonia romana a la medina musulmana. Palma: José J. de Olañeta.

Murray, D. G.; Pascual, A. y Llabrés, J. 1992. Conventos y Monasterios de Mallorca. Historia, Arte y Cultura. Palma: José J. de Olañeta editor.

Noguera Giménez, J. F. 2000. «El centro histórico de Valencia como modelo de ciudad conventual», en S. Dauksis Ortolá y F. Taberner Pastor, F (eds.), Historia de la ciudad. I: recorrido histórico por la arquitectura y el urbanismo de la ciudad de Valencia: 90-115. Valencia: Colegio Oficial de Arquitectos de la Comunidad Valenciana.

Novo Malvárez, M. 2016. Los conventos de clausura del centro histórico de Palma. Potencialidades y nuevos usos vinculados a la gestión de su patrimonio cultural. Tesis doctoral. Palma de Mallorca, Universitat de les Illes Balears.

http://www.tesisenred.net/handle/10803/396208 [Consulta: 20-05 -2017].

Olmedo Sánchez, Y. V. 2012. «De la ciudad conventual a la ciudad burguesa: las órdenes religiosas en la evolución urbana de Córdoba». Hispania Sacra 64 (129): 29-66. https://doi.org/10.3989/hs.2012.002

Pascual, A. y Llabrés, J. 1996. El Monasterio de Santa Teresa de Jesús de Palma. Una fundación en la ciudad del Seiscientos. Palma: Ajuntament de Palma.

Pérez Cano, M. T. 1996. Patrimonio y ciudad. El sistema de los conventos de clausura en el centro histórico de Sevilla. Génesis, diagnóstico y propuesta de intervención para su recuperación urbanística. Sevilla: Fondo de Cultura de Sevilla y Publicaciones de la Universidad de Sevilla.

Pérez Cano, M. T. y Mosquera Adell, E. 1991. Arquitectura en los conventos de Sevilla. Una introducción patrimonial a las clausuras. Sevilla: Consejería de Cultura.

Riera Frau, M. M. 1993. Evolución urbana y topografía de Madina Mayurqa. Palma: Ajuntament de Palma.

Rodríguez Molina, J. 2012. "Granada, ciudad conventual: Granada, conventual city», en R. Marin López (coord.), Homenaje al Profesor Dr. D. José Ignacio Fernández de Viana y Vieites: 473-488. Granada: Universidad de Granada.

Rosselló Bordoy, G. 2007. Documents cabdals del Regne de Mallorca. Llibre del Repartiment de Mallorca o Llibre del Rei (ARM, 18), Salamanca.

Sastre Barceló, J. C. 2006. Espiritualitat i vida quotidiana al Monastir de Santa Clara. Ciutat de Mallorca, segles XIII-XV. Palma: Lleonard Muntaner editor.

Seguí Aznar, M. 1990. Arquitectura Contemporánea en Mallorca (1900-1947). Palma: Universitat de les Illes Balears y Col-legi Oficial d'Arquitectes de les Balears.

Seguí Beltrán, A. 2011. «Els oficials de la fortificación de Ciutat de Mallorca (1594-1610)». Bolletí de la Societat Arqueològica Lul.liana 67: 183-191.

Tous Meliá, J. 2002. Palma a través de la cartografía (1596-1902). Palma: Ajuntament de Palma.

Tous Meliá, J. 2004. «La evolución urbana de Palma, una visión iconográfica». Biblio 3 W. Revista Bibliográfica de Geografía y Ciencias Sociales IX (518): 1-11.

Zaforteza y Musoles, D. 1953. La ciudad de Mallorca. Ensayo Histórico Toponímico. Palma: Ayuntamiento de Palma. 